\title{
Clinical Pharmacist assessment in the prophylaxis of venous thromboembolism in a university hospital
}

\author{
Julia de Souza GOMES ${ }^{1}$, Rita de Cássia CORNÉLIO'${ }^{1}$,Soraida Sozzi MIGUEL ${ }^{1}$ \\ ${ }^{1}$ Faculdade de Ciências Médicas e da Saúde de Juiz de Fora, Minas Gerais, Brasil \\ Corresponding Author: Gomes JS, juliadsgf@gmail.com \\ Submitted: 16-01-2021 Resubmitted: 17-03-202 Accepted: 17-03-2021 \\ Peer review: Maria Auxiliadora Parreiras-Martins and Guilherme Vaz de Melo
}

\begin{abstract}
Objetive: to evaluate the adherence of health professionals to interventions by the clinical pharmacist service in the prevention of venous thromboembolism in a teaching hospital. Methods: This is a retrospective study in which, through data collection and analysis statistics (considering $p<0.05$ as the level of significance), pharmaceutical therapies related to drug prescription related to prophylaxis of venous thromboembolism (following the protocol in force at the institution) for patients admitted to a teaching hospital in Minas Gerais from December 2019 to August 2020.. The level of acceptance of clinical pharmacy interventions regarding the need to prescribe prophylactic anticoagulants, change in anticoagulation dosage, prescription of two or more anticoagulants and the lack of risk classification was evaluated for the development of venous thromboembolism for inpatients. Results: in the nine-month period, 62 pharmaceutical interventions were performed before the clinical staff, with $82.25 \%$ adherence: need for prescription of anticoagulants (82.75\%); change in anticoagulation dosage (80\%) and prescription of two or more anticoagulants (100\%). In the same period, 2070 interventions (100\%) with the nursing team were identified regarding the lack of risk classification for the development of venous thromboembolism for patients admitted via the RM Saude system. Conclusion: the evaluation allowed to identify the importance of the clinical pharmacist in the prevention of thromboembolic events for patients admitted to a hospital.
\end{abstract}

Key words: venous thromboembolism; pharmacy service; hospital; anticoaguants.

\section{Avaliação farmacêutica clínica na profilaxia de tromboembolismo venoso em um hospital de ensino}

\begin{abstract}
Resumo
Objetivo: avaliar a adesão dos profissionais de saúde às intervenções do serviço do farmacêutico clínico na prevenção do tromboembolismo venoso em um hospital de ensino. Métodos: trata-se de um estudo retrospectivo no qual foram avaliadas, através de coleta de dados e análise estatística (considerando $p<0,05$ como nível de significância), as intervenções farmacêuticas referentes à prescrição medicamentosa relacionadas à profilaxia de tromboembolismo venoso (seguindo o protocolo vigente na instituição) para pacientes internados em um hospital de ensino de Minas Gerais no período de dezembro de 2019 a agosto de 2020. Foi avaliado o nível de aceitação das intervenções da farmácia clínica referentes à necessidade da prescrição de anticoagulantes profiláticos, mudança da posologia da anticoagulação, prescrição de dois ou mais anticoagulantes e a falta da classificação de risco para o desenvolvimento de tromboembolismo venoso para os pacientes internados. Resultados: no período de nove meses foram realizadas 62 intervenções farmacêuticas perante o corpo clínico com 82,25\% de adesão: necessidade da prescrição de anticoagulantes (82,75\%); mudança da posologia da anticoagulação (80\%) e prescrição de dois ou mais anticoagulantes (100\%). No mesmo período foram identificadas 2070 intervenções (100\%) com a equipe de enfermagem sobre a falta da classificação de risco para o desenvolvimento de tromboembolismo venoso para os pacientes internados via sistema RM Saúde. Conclusão: a avaliação permitiu identificar a importância do farmacêutico clínico diante da prevenção de eventos tromboembólicos para pacientes internados em um hospital.
\end{abstract}

Palavras-chave: tromboembolia venosa; serviço de farmácia hospitalar; anticoagulantes. 


\section{Introduction}

VTE (Venous Thromboembolism) is considered one of the main causes of preventable mortality in hospitalized patients; it is classified as deep vein thrombosis (DVT) and as pulmonary thromboembolism (PTE), the latter being its most serious immediate consequence. ${ }^{1}$ Approximately one third of the hospitalized patients are at risk of developing DVT; however, this number can be significantly reduced with adequate prophylaxis. ${ }^{2}$

Some nosocomial institutions show evident negligence regarding thrombosis prophylaxis, even in reputable hospitals with highly qualified physicians. ${ }^{3}$ Thus, even with the education of health professionals on the subject matter, VTE remains a problem for patient safety. ${ }^{4}$

There are strategies that can be adopted in hospitals to increase adherence to the prescription of prophylaxis for hospitalized patients and consequently reduce the risk of developing VTE, which include: risk classification, ${ }^{4}$ use of electronic alerts, ${ }^{5}$ participation of the Nursing team ${ }^{6}$ and active participation of pharmacists. ${ }^{7}$

Clinical pharmacists can contribute to the prevention of VTE, as they are part of the multidisciplinary team, participate in bedside visits, do pharmacotherapy monitoring of patients by analyzing prescriptions (potential drug interactions, drug incompatibilities, dose, dosage, schedule, medication reconciliation, allergies, renal dose adjustment, etc.) and streamline the process for purchasing non-standard drugs at the institution, when necessary. ${ }^{8}$ Considering the cost of treating patients who develop VTE during hospitalization, managers and administrators are concerned with making better use of the existing resources, which can be done with the effective participation of the pharmacists in the application of their knowledge of pharmacoeconomics. ${ }^{9}$

Given the scarce evidence on the management of increased rates of prophylaxis of thrombotic events, this study aims to analyze the level of acceptance of pharmaceutical interventions related to the VTE protocol among the multidisciplinary team, highlighting the importance of pharmacotherapy follow-up in hospitalized patients in order to avoid rehospitalization, complications and deaths.

\section{Methods}

A retrospective study based on interventions performed by the pharmacist with patients at risk classified for the development of venous thromboembolism in the period between December 2019 and August 2020 in a teaching hospital in the state of Minas Gerais, Brazil. The hospital is classified as large, with 290 beds exclusively devoted to patients from the Unified Health System (Sistema Único de Saúde, SUS), providing health care in several specialties and offering complete and highly-complex care. The hospital's clinical pharmacy service monitors the patients' pharmacotherapeutic care on a criticality scale by analyzing the prescriptions, considering the medical conduct and the patient's clinical condition.

During the patient's hospitalization, the Nursing team identified the risk factors for VTE (Recent abortion, Ischemic or hemorrhagic stroke, Hormonal contraceptives, Active cancer, Central venous catheter, Recent surgery, Inflammatory bowel disease, Chronic Obstructive Pulmonary Disease, Active rheumatic disease, Age 55+, Immobilization, Current acute myocardial infarction, Infection/Sepsis,
Peripheral arterial failure, Class III or IV heart failure, Respiratory failure, Admission to the Intensive Care Unit, Obesity (BMI>30), Paresis or paralysis of lower limbs, Puerperium (up to 4 weeks), Chemotherapy, Hormone replacement, Nephrotic syndrome, previous VTE, Thrombophilia, Varicose veins/Peripheral venous insufficiency) in the RM Saúde system, generating the risk classification (low, moderate and high) in the patient's electronic medical record. In case classification was not done, it was communicated via email to the lead nurse so that he/she could make the classification.

Daily, the clinical pharmacist analyzed the prescriptions of patients older than 18 years of age admitted to the institution, considering the risk classification for VTE, absence or presence of anticoagulants; anticoagulation dosage; therapeutic duplicity (prescription of two or more anticoagulants) ${ }^{10}$ and the patient's clinical condition (reduced mobility, contraindications, etc.). In cases where the medical decision was not in accordance with the current protocol, the clinical pharmacy resident student addressed the lead physician and they chose the best conduct for the patient via the electronic medical record. The intervention was considered as accepted in case the patient did not present any contraindication: hypersensitivity to heparins, heparininduced thrombocytopenia, active bleeding, already using full anticoagulation, spinal block or CSF (Cerebrospinal Fluid) collection $<2$ hours ago, recent intracranial or eye surgery, CSF collection in the last 24 hours, hemorrhagic diathesis (alteration of platelets or coagulogram), uncontrolled arterial hypertension (>180x110 $\mathrm{mmhg}$ ), renal failure (clearance $<30 \mathrm{~mL} / \mathrm{min}$ ).

The data were compiled and statistically analyzed in a Microsoft Office Excel ${ }^{\circledR}$ spreadsheet. The variables were expressed in the form of absolute ( $n$ ) and relative (\%) frequency, adopting $p<0.05$ as significance level by the chi-square test. This study was approved by the Committee of Ethics in research with human beings of the Medical and Health Sciences School of Juiz de Fora under CAAE opinion No. 38302220.0.0000.5103.

\section{Results}

In the nine-month period, 26,114 prescriptions were analyzed and 2,132 pharmaceutical interventions were performed. Most of the interventions (97\%) were related to the lack of risk classification by the Nursing team with an adherence rate of $60.9 \%$. The other interventions were made with the clinical staff: therapeutic duplicity, with $100 \%$ adherence; change of dosage, with $80 \%$, and need for prescription, with $82.8 \%$.

Patients without the risk classification in their electronic medical records were signaled via email by the clinical pharmacy so that the Nursing team would make the classification and the medical team could assess the patient's clinical condition and prescribe the best therapy.

Prescriptions with double anticoagulation ${ }^{10}$ were analyzed. If they had no indication for such therapeutic approach, it was suggested to suspend one of the anticoagulants.

Patients classified as at high risk have an indication for the prescription of UFH (unfractionated heparin) $8 \times 8$ hours or LMWH (low molecular weight heparin) $40 \mathrm{mg}$ once a day. In these cases, if UFH was prescribed with a different dosage or when LMWH was prescribed with a therapeutic dosage or dose, with prophylactic indication, interventions were carried out to readjust the prescription. 
Patients classified as at medium or high risk without a prescription of anticoagulation with no contraindications specified in electronic medical records require pharmacological prophylaxis, so interventions were conducted suggesting the prescription. That is, the pharmacist included prophylaxis in 24 cases that required prophylactic anticoagulation.

In the 9-month period, 9,905 patients were followed-up, most of them classified as at moderate risk of VTE (50.1\%), followed by low (30\%) and high (7\%) risk. $12.9 \%$ of the patients did not have their risk classified. Among the standard prophylactic anticoagulants, UFH was the most prescribed (31.6\%) among the physicians.

Regarding the patients who needed pharmaceutical intervention (58 patients), $55 \%$ were female and $45 \%$ were male. Patients older than 60 years of age had a greater need for intervention (79.91\%), followed by those between 41 and 59 years old (18.96\%). And in $90 \%$ of the cases, the patients presented reduced mobility, requiring prophylactic anticoagulation.

Table 1. Assessment on pharmaceutical interventions.

\begin{tabular}{|c|c|c|c|}
\hline \multirow{2}{*}{ Interventions } & \multicolumn{2}{|c|}{$\begin{array}{l}\text { Pharmaceutical } \\
\text { interventions } \mathrm{N}=2,132\end{array}$} & \multirow{2}{*}{ p-value } \\
\hline & $\begin{array}{l}\text { Accepted } \\
N=1,311\end{array}$ & $\begin{array}{l}\text { Not accepted } \\
\mathrm{N}=821\end{array}$ & \\
\hline \multicolumn{4}{|l|}{ Type of intervention $\mathbf{n}(\%)$} \\
\hline Risk classification ${ }^{15}$ & $\begin{array}{l}1,260 \\
(59.09)\end{array}$ & $810(37.99)$ & \multirow{4}{*}{0.01210} \\
\hline Double anticoagulation & $3(0.14)$ & $0(0.00)$ & \\
\hline Change in dosage & $24(1.12)$ & $6(0.28)$ & \\
\hline Need for anticoagulation & $24(1.12)$ & $5(0.23)$ & \\
\hline \multicolumn{4}{|c|}{ VTE risk classification ${ }^{15} \mathrm{n}(\%)$} \\
\hline High risk & $25(1.91)$ & $4(0.19)$ & \multirow{4}{*}{0.005200} \\
\hline Moderate risk & $25(1.91)$ & $6(0.28)$ & \\
\hline Low risk & $1(0.08)$ & $1(0.08)$ & \\
\hline Not filled out & $\begin{array}{l}1,260 \\
(59.09)\end{array}$ & $810(37.99)$ & \\
\hline \multicolumn{4}{|c|}{ Professionals contacted $\mathrm{n}(\%)$} \\
\hline Physician & $51(2.39)$ & $11(0.51)$ & \multirow[b]{2}{*}{0.000649} \\
\hline Nurse & $\begin{array}{l}1,260 \\
(59.09)\end{array}$ & $810(37.99)$ & \\
\hline \multicolumn{4}{|c|}{ Place where it was made $n(\%)$} \\
\hline Patient's medical record & $51(2.39)$ & $11(0.51)$ & \multirow[b]{2}{*}{0.000649} \\
\hline E-mail & $\begin{array}{l}1,260 \\
(59.09)\end{array}$ & 810 (37.99) & \\
\hline
\end{tabular}

\section{Discussion}

The findings of this study show that $61.49 \%$ of the interventions proposed by the clinical pharmacist were accepted by the Nursing team (62.2\%) and by the clinical personnel (82.5\%). The low adherence by Nursing can be justified by the high turnover in the unit, requiring training for the new employees.

Evidence shows that patients admitted to the hospital may not receive adequate VTE prophylaxis and that the use of prophylactic anticoagulation reduces the incidence of thrombotic events in these patients. ${ }^{11,12,13}$ A total of 29 interventions were performed by the clinical pharmacist requesting the prescription of anticoagulants for patients who were without prophylaxis, with $80 \%$ adherence, and 30 interventions suggesting a change in the dosage of the medication, with $82.8 \%$ adherence.
Risk stratification must occur in patients admitted to the hospitals or who have been hospitalized for a certain period to ensure an adequate prophylaxis prescription..$^{13}$ The most frequent type of intervention in this study was to request a risk classification for VTE (97\%).

It is worth mentioning that, with the concern of the high costs generated by the hospitalization, hospital discharges occur increasingly earlier in time, with higher incidence of VTE home cases after hospital discharge. In some cases, it is necessary to use prophylaxis for a certain period after hospitalization. ${ }^{14}$ This study did not include treatment and post-discharge.

\section{Conclusion}

This study identified the interventions performed in order to offer the best therapy for the patient by inserting prophylactic anticoagulants for patients who needed but were not using them, requesting a change in dosage according to the patient's risk and clinical condition, excluding the prescription anticoagulant if there was unnecessary duplication and requesting the risk classification of the patients. In view of the above, the role of the Clinical Pharmacist is effective in the prevention of complications and, consequently, in the reduction of the number of deaths, in addition to reducing costs during hospitalization and after hospital discharge.

\section{Funding sources}

This research did not receive funding for its accomplishment.

\section{Collaborators}

JSG: Conception and design or analysis and interpretation of data. Writing of the article or relevant critical review of the intellectual content. RCC, SSM: Writing of the article or relevant critical review of the intellectual content.

\section{Conflict of interests statement}

The authors declare that there are no conflicts of interest regarding this article.

\section{References}

1. Kahn SR, Lim W, Dunn AS, et al. Prevention of VTE in nonsurgical patients: Antithrombotic Therapy and Prevention of Thrombosis, 9th ed: American College of Chest Physicians Evidence-Based Clinical Practice Guidelines. Chest. 2012;141(2 Suppl):195S-226S.

2. Anderson FA Jr, Zayaruzny M, Heit JA, et al. Estimated annual numbers of US acute-care hospital patients at risk for venous thromboembolism. Am J Hematol. 2007;82(9):777-82.

3. Goldhaber SZ, Turpie AG. Prevention of venous thromboembolism among hospitalized medical patients. Circulation. 2005;111(1):1-3. 46 - Raimundo SRO, Lobo SMA, Hussain KMK, Hussein HG, Isabela TS. O que mudou nas ultimas décadas na profilaxia do tromboembolismo venoso em pacientes internados: artigo de revisão. J Vasc Bras. 2019.

4. Raimundo SRO, Lobo SMA, Hussain KMK, et al. O que mudou nas ultimas décadas na profilaxia do trmboembolismo venoso 
em pacientes internados: artigo de revisão. J Vasc Bras. 2019.

5. Kucher N, Koo S, Quiroz R, et al. Electronic alerts to prevent venous thromboembolism among hospitalized patients. N Engl J Med. 2005;352(10):969-77.

6. Gibbs $\mathrm{H}$, Fletcher J, Blombery $\mathrm{P}$, et al. Venous thromboembolism prophylaxis guideline implementation is improved by nurse directed feedback and audit. Thromb J. 2011;9(1):7.

7. Bauer JB, Chun DS, Karpinski TA. Pharmacist-led program to improve venous thromboembolism prophylaxis in a community hospital. Am J Health SystPharm. 2008;65(17):1643-7.

8. Haga CS, Mancio CM, Pioner MC, et al. Implantação do serviço do farmacêutico clínico vertical na profilaxia do tromboembolismo venoso em pacientes clínicos hospitalizados. Einstein. 2014;12(1):27-30.

9. Andrade EO, Binda FA, Silva AMM, et al. Fatores de risco e profilaxia para tromboembolismo venoso em hospitais da cidade de Manaus. J BrasPneumol. 2009;35(2):114-121.

10. Melo DO, Miolino CGRC, Ribeiro E, Romano-Lieber NS. Capacitação e intervenções de técnicos de farmácia na dispensação de medicamentos em Atenção Primária à Saúde. Ciência \& Saúde Coletiva, 22(1):261-268, 2017.

11. Lopes BAC, Teixeira IP, Souza TD, Tafarel JR. Sabemos prescrever profilaxia de tromboembolismo venoso nos pacientes internados?.J Vas Bras.2017;16(3):199-204

12. Samama MM, Cohen AT, Darmon JY, et al. A comparison of enoxaparin with placebo for the prevention of venous thromboembolism in acutely ill medical patients. Prophylaxis in Medical Patients with Enoxaprin Study Group. N Engl J Med. 1999;341(11):793-800. http:// dx.doi.org/10.1056/ NEJM199909093411103. PMid:10477777.

13. Curtarelli A, Correia e Silva LP, Camargo AB, et al. Profilaxia de tromboembolismo venoso, Podemos fazer melhor? Perfil de risco e profilaxia de tromboembolismo venoso em Hospital Universitário do interior do Estado de São Paulo. J Vas Bras. 2019.

14. Carneiro JLA; Targueta GP; Marino LO. Avaliação da profilaxia do tromboembolismo venoso em hospital de grande porte. Rev Col Bras.2010;37(3):204-210.

15. Jacobson BF, Louw S, Büller $\mathrm{H}$, et al. Venous thromboembolism: Prophylactic and therapeutic practice guideline. Southern African Society of Thrombosis and Haemostasis. 2013;103(4):260-267. 